\title{
'Ought' implies 'can' and the principle of alternate possibilities
}

\section{Gideon YAFFe}

In his paper 'What we are morally responsible for', ${ }^{1}$ Harry Frankfurt claims, in passing, that while the 'Frankfurt Counterexamples' 2 are counterexamples to the Principle of Alternate Possibilities (PAP: An agent is morally blameworthy ${ }^{3}$ for what she has done only if she could have done otherwise), they are not counterexamples to the famous Kantian maxim that 'Ought' implies 'Can'. In an Analysis paper of a few years ago, David Widerker objected to Frankfurt's claim by arguing that the 'Ought' implies 'Can' maxim (The Maxim: If an agent is morally obligated to act in a particular way, then the agent has the ability to act in that way) entails PAP; hence, counterexamples to PAP are counterexamples to the Maxim as well. ${ }^{4}$

Widerker's argument points to a serious problem for those who believe that PAP is to be rejected for roughly the reasons that Frankfurt suggests, even though the Maxim is to be maintained. Such a position might be important for what John Fischer has termed 'actual sequence' views of freedom: ${ }^{5}$ views that see the status of an action as free or unfree as depend-

1 Reprinted in The Importance of What We Care About, Cambridge University Press, Cambridge, 1988. The remark concerning the relationship between 'Ought' implies 'Can' and PAP is on pp. 95-96.

2 Frankfurt's first presentation of Frankfurt Counterexamples is in 'Alternate possibilities and moral responsibility' in Journal of Philosophy, 66 (1969) 828-39. In all such examples, a person chooses to perform some morally reprehensible action and does perform it, despite the fact that a pernicious and unactivated force waits in the wings to insure that she would have so chosen and acted had she not reached the decision on her own. Frankfurt claims that such examples show that PAP is false: agents can be morally responsible for reprehensible conduct even when they cannot do otherwise.

3 The notion of moral responsibility comprehends both praise and blame, and it is possible that, with respect to PAP, the two cases should be treated differently. For the purposes of this paper, I am considering only blame for wrong conduct and leaving aside the issue of the necessary conditions of praise for praiseworthy conduct. (Relevant to this point is Susan Wolf's, 'Asymmetrical freedom' in Moral Responsibility, edited by J. M. Fischer, Cornell University Press, Ithaca, 1986, pp. 225-40.)

4 David Widerker, 'Frankfurt on 'ought implies can' and alternative possibilities' in Analysis, 51 (1991) 222-24.

5 See, particularly, John Fischer, The Metaphysics of Free Will, Blackwell, Oxford, 1994. Cf. pp. 148-49, 157-58. 
ing only on features of the actual causal sequence leading to the action and not on features of possible, unactualized, causal sequences. Although those who defend actual sequence views might simply reject the Maxim, the fact that the Maxim does not appeal to unactualized possibilities - for all that the Maxim says, an agent can have and discharge an obligation even if nothing other than what she actually did was possible - suggests that there might be room within an actual sequence position to accommodate the strong pre-theoretic intuitions favouring the truth of the Maxim. However, actual sequence views must reject $\mathrm{PAP}^{6}$ - since, according to PAP, an agent cannot have or discharge an obligation unless an unactualized causal sequence leading to an alternative action was possible - and so actual sequence views can be strengthened - or, at least, given room to be strengthened - through denial of the implication from the Maxim to PAP. ${ }^{7}$ As I'll argue here, while a principle similar to the Maxim does imply a principle similar to PAP, it is not the case that the Maxim implies PAP - at least not for the reasons that Widerker suggests.

Widerker argues for the implication as follows:

(1) An agent is morally blameworthy for what she has done only if she had a moral obligation not to do as she did.

(2) An agent was morally obligated not to do as she did only if it was within her power to act differently from the way she did act. (From the Maxim)

(3) Therefore, PAP (from (1) and(2))

The first thing to note is that Widerker is concealing one of his steps, and, as I argue, it is the concealed step that requires the severest scrutiny. The argument should read as follows:

(1') An agent is morally blameworthy for what she has done only if she had a moral obligation not to do as she did. (Equivalent to (1))

${ }^{6}$ To be sure, the ability to do otherwise can be analysed in a way consistent with actual sequence views, but there are also various natural interpretations of the notion under which PAP cannot be held by anyone who adheres to an actual sequence view.

7 Recently - in 'Defending the principle of alternate possibilities: blameworthiness and moral responsibility' in Noûs 31:4 (1997) 441-56 - David Copp has extended Widerker's argument by claiming that our attachment to the Maxim supersedes our attachment to the intuitions that we tend to have when considering Frankfurt Counterexamples. Since accepting the veridicality of our intuitions with regard to the Frankfurt Counterexamples would require the rejection of the Maxim (assuming, as Copp and Widerker claim, that the Maxim implies PAP), Copp argues that we ought to reject the intuitions with regard to the counterexamples, thus accepting both the Maxim and PAP. 
(2') An agent was morally obligated not to act as she did only if she was morally obligated to act differently from the way she did act.

(3') An agent was morally obligated to act differently from the way she did act only if it was within her power to act differently from the way she did act. (From the Maxim)

$\left(4^{\prime}\right)$ Therefore, PAP (from (1), (2) and (3))

The step missing from Widerker's treatment of the argument is $\left(2^{\prime}\right)$, and, as it turns out, $\left(2^{\prime}\right)$ is false. Here's why: Let's say that I'm morally obligated not to A. Then I avoid moral transgression just in case I do not A. Does it follow, as Widerker requires, that I am morally obligated to do something other than A? Imagine that there is some act that I am obligated not to perform at midnight while I am soundly asleep. According to $\left(2^{\prime}\right)$, the fact that I was morally obligated not to act in a certain way at midnight implies that I was morally obligated to perform a different action at that time. There is only one action that I can possibly be construed as performing at midnight - sleeping - and that action is not something (we can assume) that I was morally obligated to do, hence I cannot have discharged any moral obligation by doing it. ${ }^{8}$ If $\left(2^{\prime}\right)$ is true, there must be some other morally obligatory action that I failed to perform at midnight, and, hence, I shirked a moral obligation at that time. Since I shirked no moral obligations at midnight, it follows that $\left(2^{\prime}\right)$ is false.

Widerker's argument gains force only by generating an obligation to perform a particular action different from that I am obligated not to perform. But morality doesn't require that I consider, reject and take steps to prevent the occurrence of all the things that I am obligated not to do. I ought not to send money to support unjust foreign wars, but that doesn't mean that I ought to investigate all such possible wars and resolutely decide not to send any money to support them; it's good enough to simply not know about them and not do anything to support them. An obligation not to perform a particular action does not, in general, generate an obligation to do something else instead.

It is worth applying the objection that I am making to a Frankfurt Counterexample. Since David Copp is one person who has recently embraced Widerker's argument, I'll use his Frankfurt example: A woman, Madeleine, lies in order to avoid embarrassment, but an ominous presence, Count Vener, would have caused her to feel sufficient embarrassment to make her lie should he have predicted that she would not. Since he is a mere (count)erfactual inter(vener), he never has to exercise his diabolical powers. Copp agrees, for the sake of argument, that Madeleine could not

8 The point should have equal weight for those who deny that sleeping is an action. If I did nothing at all at midnight I surely didn't fulfill any moral obligations to act in particular ways. 
have refrained from lying; there was no action that she could have performed, in all the relevant senses of 'could', which would have resulted in her not lying. Copp then applies Widerker's argument to conclude that if Madeleine is morally blameworthy for lying, then the Maxim is false. ${ }^{9}$

Intuitively, Madeleine violated a moral obligation not to lie. We might say, with Widerker and Copp, that she was therefore obligated to do something other than lie, and, since she couldn't, either our intuition is faulty or the Maxim is false. But was she obligated to do something other than lie? If she wouldn't be under an obligation to do something other than lie were Count Vener absent, his presence certainly can't generate a further obligation, and in the circumstance in which Count Vener is absent there is no reason to think that her obligation not to lie generates an obligation to do something else, for just the reasons discussed above: Were she knocked unconscious at just the right moment she wouldn't do anything at all, but she wouldn't shirk any obligation to do something other than lie. Hence, the fact that Madeleine is blameworthy for lying does not imply that the Maxim is false, at least, not for the reasons proposed by Widerker.

Understood strictly, the Maxim says nothing at all about the nature of the abilities necessary for an agent to be under an obligation not to act in a particular way; the Maxim seems to apply only to cases in which the object of the 'ought' is an action, and in cases in which we are obligated not to act in some particular way, the object of the 'ought' is rather absence of action, a state of affairs that can be realized without any action at all. (Widerker tries, illegitimately I've claimed, to bring the Maxim into play with respect to an obligation not to act, by sliding from an obligation not to act, to an obligation to act in some other way.) But it is worth asking if there is a principle very much like the Maxim that applies to obligations not to act. And, indeed, there is a natural way to formulate such a principle:

New Maxim: If an agent ought not to A then it is possible $\mathrm{e}^{10}$ that the agent fails to A.

Does the New Maxim imply PAP for something like the reasons Widerker suggests? No, for PAP says not merely that some world in which the agent

9 Copp, as pointed out in $\mathrm{fn} .7$, continues the argument with the claim that the intuitions that we have about cases like Madeleine's are superseded by the intuitions that we have favouring the Maxim. Thus it is the latter set of intuitions, rather than the former, that are to be given serious weight.

${ }^{10}$ Here 'possible' means that there is a possible world in which the action does not occur and in which the relevant actual circumstances are held fixed. In many of these possible worlds the agent performs no alternative action, strictly speaking, at all. A remaining question, which I will not address, is which of the features of the actual world are 'relevant' enough to be held fixed. 
did not act must have been possible for moral blameworthiness, but that $a$ world in which the agent acted differently must have been possible. ${ }^{11}$ That is, Widerker's line of reasoning supports an implication from the New Maxim not to PAP, but only to a weak version of PAP:

Weak PAP: An agent is morally blameworthy for what she has done only if it was possible that she should not have done as she did. ${ }^{12}$

But notice that even Weak PAP is impugned by the Frankfurt Counterexamples. It is not possible that Madeleine should have failed to lie (in the relevant sense of possible) for only two possible worlds are relevant here: that in which Madeleine lies under her own power and that in which Count Vener has to intervene to bring it about that she lies; in both, she lies. So, it follows that Frankfurt Counterexamples are counterexamples to the New Maxim, since they are counterexample to Weak PAP.

However, this leaves a question: While it is clear enough that the Maxim is deeply entrenched in our commonsense moral thought, is the New Maxim similarly entrenched? If so, then the Frankfurt counterexamples do generate a genuine tension in our commonsense moral thought. If not, however, then there is no loss in rejection of Weak PAP, for rejection of the New Maxim is not rejection of anything about which we really care. We might wonder, however, what it is, exactly, that makes the Maxim so attractive. Perhaps, when we determine what that is, we will see that the New Maxim is attractive for just the same reasons and so can't be rejected so cavalierly. What has been shown here, however, is that there is space to defend the Maxim and reject PAP, as defenders of 'actual sequence' views might hope to do; but such a view requires further support in the form of a story as to why the Maxim is indispensable, a story that cannot be told just as well about the New Maxim. ${ }^{13}$

\section{University of Southern California Mudd Hall of Philosophy Los Angeles, CA 90089-0451, USA yaffe@usc.edu}

11 As is probably clear by now, a world of the former sort could be possible without the possibility of a world of the latter sort, since the agent might fail to act as she did without acting in any way at all.

12 Here 'possible' is to be understood in the same way as that described in fn. 10 .

13 Thanks to Michael Bratman, John Fischer, Paul Hoffman, Peter Smith and anonymous reviewers for this journal, all of whom gave useful comments on earlier versions of this paper. Thanks also to David Copp for his comments, and for an extensive and fascinating e-mail correspondence concerning the topics of this paper. 